\title{
Convergent evolution of sex-specific leg ornaments in Drosophilidae - from cells to structures.
}

\author{
K. Tanaka ${ }^{1 *}$, O. Barmina ${ }^{1}$, J. H. Massey ${ }^{2,3}$, and A. Kopp ${ }^{1}$ \\ 1 Department of Evolution and Ecology, University of California - Davis, Davis CA USA \\ 2 Department of Ecology and Evolutionary Biology, University of Michigan, Ann Arbor MI \\ USA \\ 3 Janelia Research Campus, Howard Hughes Medical Institute, Ashburn VA USA \\ * Corresponding author: kohtanaka@ucdavis.edu
}

\begin{abstract}
Sexually dimorphic morphological traits are among the fastest evolving animal features. Similar sex-specific structures have sometimes evolved independently in multiple lineages, presumably as targets of parallel sexual selection. In such cases, comparing the cellular mechanisms that generate these structures in different species can elucidate the interplay between selection and developmental constraint in evolution. In Drosophilidae, malespecific tarsal brushes on the front legs are found in at least four separate lineages. In this study, we combine phylogenetic reconstruction with developmental analyses and behavioral observations to investigate the evolutionary origin of these structures. We show that the sex brush has evolved independently at least three times from sexually monomorphic ancestral morphology. However, all sex brushes have very similar fine structure and develop through indistinguishable cellular processes, providing a striking example of developmental convergence. In all examined species, males use their sex brushes to grasp the female abdomen prior to copulation. We discuss potential reasons why convergent evolution of novel structures is rare even in the face of similar functional demands.
\end{abstract}

Keywords: Drosophila phylogeny; sexual dimorphism; convergent evolution; mating behavior; bristle development 


\section{Introduction}

46 Most animals are sexually dimorphic. Perhaps the most fascinating feature of sexual 47 dimorphism is the rapid evolutionary turnover of sex-specific traits. Even among close relatives, the characters that distinguish males from females vary greatly from species to species. This simple observation implies that new sexual characters are gained, and ancestral ones are often lost, during the evolution of many if not most animal lineages. Understanding the genetic and developmental basis of this turnover is necessary to shed

52 light on one of the most important drivers of biological diversity. Examples where similar 53 traits have evolved multiple times are of particular value, as they often provide insights 54 into the general patterns and mechanisms of evolution (Kopp 2009).

Most higher Diptera mate with the male on top of the female, and the male front (T1) legs are often involved in grasping or stimulating the female (Huber et al., 2007; McAlpine, 1981). Perhaps for this reason, male-specific ornaments or grasping structures are found on the T1 legs of many dipteran species (Daugeron et al., 2011; Eberhard, 2001; Ingram et al., 2008; Sivinski, 1997). In Drosophilidae, the most obvious male-specific leg modifications include the sex combs found in the Drosophila melanogaster and obscura species groups and in the genus Lordiphosa (Katoh et al., 2018; Kopp, 2011); branched or spoon-shaped tarsi of some Hawaiian Drosophila species (Hardy, 1965; Stark and O'Grady, 2009); and tarsal brushes that are the focus of this study (Figure 1). Sex brushes are found in at least four separate groups within the Drosophilidae: the Drosophila immigrans species group, the loiciana species complex, D. repletoides, and the genus Zaprionus. Due to uncertain relationships among these lineages, the evolutionary origin(s) of this structure remain unclear.

In the immigrans group, male sex brushes are found in some but not all of the species; the most likely scenario is that the brush was present in the last common ancestor of this clade, but was secondarily lost in the nasuta subgroup and greatly reduced in several

72 species, with the exception of Z. neglectus, Z. spineus, and Z. spinosus (Tsacas and 73 Chassagnard, 1990; Yassin et al., 2008; Yassin and David, 2010). The Zaprionus phylogeny

74 is not fully resolved, but the distant relationship between the first species and the last two 
75 suggests that their lack of brushes is likely to reflect independent secondary losses. The

76 situation is more complicated among species assigned to the Oriental Anaprionus subgenus

77 of Zaprionus. Many of its members, including Z. lineosus, Z. spinilineosus, Z. orissaensis, Z.

78 multistriatus, Z. grandis, and Z. aungsani, lack leg brushes (Gupta, 1972; Kikkawa and Peng,

79 1938; Okada and Carson, 1983; Wynn and Toda, 1988). However, Anaprionus is now

80 thought to be polyphyletic (Yassin, 2007; Yassin et al., 2010), and these species appear to

81 be more closely related to the genus Xenophorticella than to Zaprionus sensu stricto (M.

82 Toda, pers. comm.). Other Anaprionus species such as Z. bogoriensis, Z. obscuricornis, and Z.

83 pyinoolwinensis have leg brushes (Mainx, 1958; Okada, 1964; Wynn and Toda, 1988) and

84 likely form a clade with the Afrotropical Zaprionus (M. Toda, pers. comm.). Thus, the leg

85 brush has evolved either at or near the base of Zaprionus.

86 D. pruinosa belongs to the loiciana species complex, which also includes D. loiciana,

87 D. allochroa, D. pachneissa, D. semipruinosa, and D. xanthochroa. All of these species have

88 male leg brushes of different sizes (Tsacas, 2002; Tsacas and Chassagnard, 2000). The

89 fourth lineage where a male leg brush is found consists of a single species, D. repletoides,

90 which does not have any known close relatives; a species described originally as $D$.

91 tumiditarsus (Tan et al., 1949) was later synonymized with D. repletoides (Hsu, 1943;

92 Wheeler, 1981). Yassin (Yassin, 2007) suggested that some species currently classified as

93 Zaprionus (Z. multistriatus, Z. flavofasciatus, and Z. cercociliaris) could in fact be more

94 closely related to $D$. repletoides than to Zaprionus; unfortunately, these species have not

95 been included in any molecular phylogenies.

96 The four clades of interest - Zaprionus, the immigrans species group, D. repletoides,

97 and the loiciana complex - have never been included together in the same molecular

98 phylogeny. Different combinations of these taxa have been examined in several

99 phylogenetic studies, which were based on a small number of loci and produced different

100 results. Da Lage et al (Da Lage et al., 2007) and Yassin et al (Yassin et al., 2010) provided

101 some evidence for a distant relationship among Zaprionus, D. repletoides, and the

102 immigrans species group. Russo et al (Russo et al., 2013) placed D. pruinosa as sister to D.

103 sternopleuralis (a member of the histrio species group that lacks a sex brush), and the

104 resulting clade as sister to the immigrans species group. The phylogenies of Da Lage et al

105 (Da Lage et al., 2007) and Izumitani et al (Izumitani et al., 2016) did not include D. pruinosa, 
106 but did not support a sister-group relationship between D. sternopleuralis and the immigrans species group.

108 In this study, we used a larger multilocus dataset to test whether the male leg brush

109 evolved independently in each of these four clades, or whether its distribution could be

110 better explained by shared origin in some of these lineages. To facilitate this analysis, we

111 included one or more representatives of each clade, as well as several brush-less species

112 that have been suggested by previous studies to be closely related to the brush-bearing

113 clades. In parallel, we compared the cellular mechanisms that produce the male leg

114 brushes in different species, as well as the role of these ornaments in mating behavior. Our

115 results strongly suggest that the sex brushes evolved convergently in several distantly

116 related lineages, but develop through virtually identical mechanisms.

\section{Materials and Methods}

Leg imaging

123 For brightfield imaging, male front legs were dissected, mounted in Hoyers media between

124 two coverslips, and photographed on a Leica DM500B microscope with a Leica DC500

125 camera. For electron microscopy, adult legs were dehydrated in 100\% ethanol, critical

126 point dried, and coated with gold. Scanning electron micrographs were taken on Thermo

127 Fisher Quattro S and Philips XL30 TMP.

Sequence data collection

131 The sources of live Drosophila strains, fixed specimens, and unpublished genome 132 assemblies used in this study are listed in Table S1. DNA was extracted from live or 133 alcohol-fixed flies using an affinity resin based protocol (Hi Yield® Genomic DNA Mini Kit,

134 Süd-Laborbedarf Gauting, Germany). PCR was carried out using DreamTaq polymerase 135 (Thermo Fisher) and the following cycling conditions: $95^{\circ} 5^{\prime}=>\left(95^{\circ} 30^{\prime \prime}=>55^{\circ} 30^{\prime \prime}=>72^{\circ}\right.$ $\left.13680^{\prime \prime}\right) \times 35=>72^{\circ} 5^{\prime}=>12^{\circ}$; the loci and primer sequences are listed in Table S2. In some 
137 cases, two rounds of PCR with nested primers were needed to obtain amplicons from fixed

138 specimens. Amplified fragments were gel-purified and sequenced from both ends using 139 amplification primers. Sequence chromatograms were trimmed in SnapGene Viewer, and 140 the two end reads were aligned and edited in Geneious. Heterozygous nucleotide positions, 141 if present, were represented by IUPAC ambiguity codes. All new sequences were deposited 142 in Genbank under accession number listed in Table S1. Additional sequences were 143 obtained from Genbank or extracted from whole-genome assemblies using Blast v2.2.23 144 (Table S1).

Sequence analysis

148 The sequences of each locus were aligned using the MUSCLE algorithm (Edgar, 2004) 149 implemented in Geneious (Kearse et al., 2012). The alignments were trimmed at the ends, 150 and poorly aligning intronic regions were removed. The alignments of all eight loci were 151 then concatenated for combined analysis. Combined Bayesian analysis was carried out in 152 MrBayes v3.2.6 (Ronquist et al., 2012). Two sets of analyses were conducted. In the first, 153 the dataset was partitioned by gene, and each locus was allowed to follow a different 154 nucleotide substitution model with empirically estimated parameters. In the second, we 155 partitioned the dataset by gene and by codon position, and used PartitionFinder with the 156 PhyML algorithm (Guindon et al., 2010; Lanfear et al., 2012; Lanfear et al., 2017) to identify 157 the appropriate partitioning scheme; this resulted in a total of 21 character subsets, each of 158 which was subsequently allowed to follow its own substitution model with empirically 159 estimated parameters. For each analysis, two parallel runs of 1,500,000 generations, each 160 starting from a different random tree, were carried out, and convergence was confirmed by 161 comparing tree likelihoods and model parameters between the two runs. D. melanogaster 162 was used as outgroup. Trees were sampled every 1000 generations and summarized after 163 a 20\% relative burn-in. Each analysis was also repeated after excluding D. quadrilineata 164 (see Results). Samples of probable trees were extracted from the tprobs file, and a strict 165 consensus of most probable trees with combined posterior probabilities of 95\% or 99\% 166 was constructed from these sets of trees in Geneious. Consensus trees were then formatted 167 using FigTree v1.3.1 (http://tree.bio.ed.ac.uk/software/figtree/). 
Immunocytochemistry and microscopy

171 Fly cultures were raised on standard Drosophila media at room temperature. Since each

172 species develops at a different rate, the timing of pupal stages was determined empirically

173 based on the morphology of transverse bristle rows (TBRs). Each species was imaged at an

174 early stage when TBR bristles of the tibia and the first tarsal segment are separated by one 175 or more intervening epithelial cells; this stage corresponds to 16 - 21 hours after 176 pupariation (AP) in D. melanogaster. Each species was also imaged at a late stage, after the 177 packing of TBRs is completed and bristle shaft differentiation is underway (corresponding 178 to $36+$ hrs AP in D. melanogaster). Pupal legs were dissected, processed and 179 immunostained as in Tanaka et al (2009). The primary antibodies used were rat anti-E180 cadherin (DCAD2, from the Developmental Studies Hybridoma Bank, at 1:20) for $D$. 181 pruinosa and Z. tuberculatus, and mouse anti-Armadillo (N2 7A1, DSHB; 1:30) for D. 182 immigrans and D. repletoides. AlexaFluor 488 secondary antibodies (Invitrogen) were used 183 at 1:400. Fluorescent images were taken on an Olympus 1000 confocal microscope and 184 processed using Image J and Adobe Photoshop. with a 105 mm AF Micro Nikkor lens. In brief, individual virgin males were isolated upon eclosion in food vials and aged for up to two weeks. Virgin females were isolated upon eclosion and housed in groups of 20-30. Pairs of males and females were then gently

192 aspirated into single wells of a 96 well culture plate (Corning 05-539-200) filled halfway 193 with a hardened 2\% agarose solution and sealed using a glass microscope slide and tape. 194 Video clips were captured at 1000 frames per second (fps) using Photron Fastcam Viewer 195 software. 


\section{Results}

Sex brush morphology is highly similar in distantly related species

In all examined species of Zaprionus, the immigrans species group, loiciana species complex, and D. repletoides, the male-specific leg brush is found on the anterior-ventral surface of the first (ta1) and sometimes also the second (ta2) tarsal segment of the prothoracic leg. In females and in other species, this area is occupied by transverse bristle rows (TBRs), which the flies use to clean their head and eyes (Tokunaga 1962; Kopp 2011).

208 The male brush replaces the distal TBRs, with a few TBRs remaining at the proximal end of ta1 (Figure 1). In the immigrans group (Rice et al. 2018) and in the other species (Figure 1), the brush shows several major differences from the TBRs. The bristles of each TBR are

211 aligned into a straight, tightly packed row that is nearly perpendicular to the proximo212 distal (PD) leg axis, while the consecutive TBRs along the PD axis are separated by many 213 cell diameters. In contrast, the modified bristles ("hairs") that make up the brush are 214 packed closely together in all directions and do not show any regular arrangement. The 215 shafts of the TBR bristles are robust and straight, with ridges and grooves running their 216 length and a triangular bract at the base; the brush hairs are thin and wavy with a smooth 217 surface, and lack bracts (Figure 1).

218 Although the morphology of the male leg brush is similar across species, detailed 219 scanning electron microscopy (SEM) analysis reveals a small but consistent difference. In $D$. 220 immigrans and D. pruinosa, the tips of brush hairs are thin and flat, taper to a point, and 221 form hooks that curve toward the base of the leg (Figure 1B, D). In D. repletoides and in 222 Zaprionus, the hair tips are noticeably thicker and curve away from the leg base (Figure $1 \mathrm{~F}$, 223 H, J, L); in Zaprionus, they are also flattened into paddle-like shapes (Figure 1 H, J, L). Thus, 224 while the spatial arrangement of bristles appears to be similar in all species, some 225 differences exist in the morphology of bristle shafts. These differences may reflect the 226 phylogenetic relationships among these taxa, especially the close relationship between $D$. 227 pruinosa and the immigrans species group (see next section). 
Male leg brushes evolved independently at least three times

We sequenced partial coding sequences of eight nuclear, protein-coding loci: acon, eno, glyp, Amyrel, Ddc, Gpdh, Pepck, and Pgm. Separate analyses of each locus produced very poorly resolved trees. We therefore combined the data from all loci (up to 9060 nucleotides per species) for a partitioned Bayesian analysis where each locus was allowed to follow its own, empirically estimated substitution model but all loci were constrained to the same tree topology. The resulting tree (Figure 2A; brush-bearing clades labeled in blue) suggests a close relationship of D. pruinosa to the immigrans species group, with the (D. sternopleuralis + D. trisetosa) clade, which belongs to the histrio species group, as the next outgroup. In contrast, D. repletoides is placed as sister group to the (D. busckii + D. brachytarsa) clade, well away from the immigrans-pruinosa lineage. Finally, the Zaprionus

242 genus is distantly related to both D. repletoides and the immigrans-pruinosa lineage, and is 243 placed near the base of the tree, separately from the Drosophila and Sophophora subgenera. 244 We also note that D. curviceps and D. annulipes appear as sister groups with 100\% support, 245 while there is no support for clustering the immigrans species group either with the $(D$. 246 curviceps + D. annulipes) clade or with D. quadrilineata (see Supplementary text). A strict 247 consensus of 11 trees with the cumulative posterior probability of $95 \%$ is not resolved near 248 the base, but does not support a close relationship among the brush-bearing lineages: $D$. repletoides, the immigrans-pruinosa clade, and Zaprionus (Figure S1).

We then examined 27 most probable trees, with the cumulative posterior probability of $99 \%$, to determine the probability of each bipartition of interest to our study.

252 The Zaprionus genus (occasionally together with D. quadrilineata; see below) was placed at 253 the base of the tree, well separated from D. repletoides and the immigrans-pruinosa lineage 254 (Figure 2A, Table S3). D. pruinosa clustered with the immigrans species group, to the exclusion of the (D. sternopleuralis + D. trisetosa) clade, with $\sim 87 \%$ probability; the 256 alternative grouping, of $D$. pruinosa with the (D. sternopleuralis $+D$. trisetosa) clade to the 257 exclusion of the immigrans species group, was observed with $\sim 13 \%$ probability. $D$. 258 repletoides was grouped with the (D. busckii + D. brachytarsa) clade with 95\% probability, 259 and this group was separated from the immigrans-pruinosa lineage by multiple internal 260 branches. In contrast, potential groupings of brush-bearing lineages - for example, of 
261 Zaprionus with either D. repletoides or the immigrans-pruinosa clade, or of the repletoides-

262 busckii-brachytarsa clade with the immigrans-pruinosa clade - were never observed among 263 this set of probable trees.

264 We noticed that among these 27 probable trees, the position of D. quadrilineata was 265 by far the most unstable. We therefore repeated the analysis after excluding this species. 266 The resulting tree (Figure 2B, Table S3) shows the same relationships as the full analysis 267 (Figure 2A), but with stronger support for most basal nodes. This tree, as well as the strict 268 consensus of the 11 most probable trees with the cumulative posterior probability of $99 \%$ 269 (Figure S2) places Zaprionus near the base of the tree, separately from the Drosophila and 270 Sophophora subgenera; D. pruinosa together with the immigrans species group and the $(D$. 271 sternopleuralis + D. trisetosa) clade; and D. repletoides in a clade that is clearly separated 272 both from Zaprionus and from the immigrans-pruinosa lineage. The probability of sister273 group relationship between D. pruinosa and the immigrans species groups is estimated at $27493.8 \% \pm 1.32 \%$ across these trees.

275 Finally, we carried out an analysis with a more complicated partitioning scheme, 276 where each locus and each codon position was allowed to follow its own substitution 277 model; this analysis was also performed with and without D. quadrilineata. In both cases, it 278 produced a tree with the same topology as in the simpler partitioning scheme, but with 279 slightly different levels of node support (Figure S3, S4 and Table S3). In summary, we find 280 substantial though not overwhelming support for a close relationship between D. pruinosa, 281 and by implication the loiciana species complex, and the immigrans species group. 282 However, based on our data, the probability of a close relationship among the different 283 brush-bearing clades - D. repletoides, Zaprionus, and the immigrans-pruinosa lineage - is 284 very low for each of the possible pairwise relationships.

The same cellular processes underlie sex brush development in all species

In D. melanogaster, TBR bristle precursors are specified between 6 and 12 hours after pupariation (AP) (Joshi and Orenic 2006, Schroff 2007). Initially, these cells are

290 specified in sparse, loosely organized rows, and separated from one another by several 291 epithelial cells. By 20-21 hrs AP, the bristle cells that are destined to make each TBR 
migrate toward each other to form a straight, contiguous row, while the intervening epithelial cells are expelled distally and proximally from the TBRs (Atallah et al. 2009; Tanaka et al. 2009). This mechanism suggests two potential explanations for the tight packing of brush hairs. One possibility is that the hair progenitor cells are specified with minimal spacing; in this case, the initial spacing between hair cells is expected to be much denser than the spacing of TBR progenitors. Alternatively, hair progenitors may first be specified similarly to TBR bristles, with wide separation by epithelial cells, but expel the epithelial cells (either laterally or basally) at later stages to form a densely packed brush. In principle, independently evolved brushes in different species could utilize different cellular mechanisms to produce adult structures that are essentially indistinguishable.

In order to characterize and compare brush development in different species, we used antibodies against membrane-localized proteins to visualize cell arrangement in 304 pupal legs. When labeled with antibodies against the beta-catenin Armadillo (Arm) or the 305 E-cadherin Shotgun (DE-cad), bristle cells can be distinguished from the surrounding epithelial cells by their unique membrane shape (Figure 3). We examined brush development at two timepoints: an early stage roughly corresponding to $\sim 16-21 \mathrm{hr}$ AP in $D$. melanogaster, when the bristle cells of the future TBRs begin to migrate toward each other and expel the intervening epithelial cells, and a later stage when cell migration is completed. We found that at the early stage, most bristle cells in the developing brush are each surrounded by four to six epithelial cells in all species. In effect, the bristle cells are

312 separated from one another by one to two epithelial cells (Figure 3). At the late stage, this spacing remains virtually invariant, although the cells appear more organized compared to

314 the early stage (Figure 3). We did not see evidence of cell migration in any of the examined 315 species. These observations indicate that despite the packed appearance similar to TBRs, 316 the brush cells are not directly adjacent to each other, are specified at high density, and 317 undergo minimal if any migration during development. Importantly, the cellular 318 mechanism of brush development is very similar in all species. 
Leg brushes are used in male mating behavior

325 High-speed video recordings show that the proximal tarsal segments of the male T1 legs,

326 including the sex brushes, are used to grab the female abdomen and resist the female's

327 efforts to dislodge the male during copulation attempts in Z. tuberculatus, D. immigrans,

328 and $D$. repletoides (Supplementary movies 1-3); unfortunately, no mating attempts were observed in D. pruinosa. In the Drosophila melanogaster species group, males use their sex combs, which are also located on the T1 tarsus, to grab the female genitalia as in $D$. melanogaster, or the middle abdominal segments as in D. kikkawai, D. ananassae, and D. bipectinata (Massey et al., 2019). In these species, male T2 and T3 legs remain on the substrate and are not involved in mating. Typically, these males proceed very quickly from mounting to attempted copulation; females may resist by walking away or using their hind legs to kick the male off. Interestingly, similar behavior is observed in D. willistoni, one of the closest relatives of the melanogaster species group that lacks sex combs (Massey et al., 2019), suggesting that the origin of the sex comb did not radically change this aspect of mating. In contrast, D. immigrans, Z. tuberculatus, and D. repletoides males use their sex brushes to grab females more anteriorly, near the constriction between the thorax and abdomen (Supplementary movies 1-3). In the former two species, males also use their T2

341 legs to grab the female mid-abdomen, while in D. repletoides T1, T2 and T3 legs are all used 342 to grab the female so that the male "rides" on the female and is not in contact with the 343 substrate. In all these species, females appear to resist mating attempts more vigorously 344 than in the melanogaster group, using side-to-side bucking and wing vibrations in apparent 345 efforts to dislodge the male, while the males use their legs to resist these efforts. The delay 346 between mounting and attempted copulation is longer in the brush-bearing species, 347 especially in $Z$. tuberculatus, than in the comb-bearing species; most mountings result in 348 the male being eventually dislodged and do not lead to copulation attempts.

A more systematic analysis, including many lineages that lack male-specific leg 350 modifications, will be needed to test whether morphological evolution correlates with the 351 evolution of behavior. At this point, we can only speculate that male leg brushes, which 352 consist of hundreds of thin hairs that are hooked at the tips and have a very large combined 
353

surface area, may have evolved to provide a more secure grip of the female abdomen, especially if stronger grip is needed to counteract the female attempts to dislodge the male.

\section{Repeated evolution of leg brushes}

\section{Discussion}

has evolved independently at least three times in Drosophilidae: in Zaprionus, in D. repletoides, and in the common ancestor of the immigrans species group and the loiciana complex, which includes D. pruinosa. Although our study does not provide unequivocal support for a sister-group relationship between D. pruinosa and the immigrans group (a closer relationship of $D$. pruinosa to the sternopleuralis-trisetosa clade cannot be completely ruled out, and of course there may exist other closely related species that we have not sampled), independent evolution of brushes in the immigrans species group and the loiciana species complex appears less likely than a single origin in a common ancestor of these clades. The proximally curving tips of brush hairs in D. pruinosa and D. immigrans, distinct from the distally curving tips in Zaprionus and D. repletoides (Fig. 1), are consistent with a close relationship between the immigrans group and the loiciana species complex.

Convergent origin of leg brushes in Zaprionus, D. repletoides, and the immigransloiciana clade is remarkable given the strong structural similarities of these brushes, and especially the fact that the cellular mechanisms that produce them in different species are essentially identical. In all species examined, the bristles that make up the sex brush are specified with only one or two intervening epithelial cells between them. Bristle specification in Drosophila and other insects is governed by a lateral inhibition mechanism, which is based on contact signaling between adjacent cells, and prevents two adjacent cells from both assuming the fate of bristle precursors (Simpson, 1990). Later in development, a tighter packing of bristles can be achieved through cell migration, as observed for example in the transverse bristle rows of the front legs (Atallah et al., 2009; Tanaka et al., 2009). However, no cell migration is observed during sex brush development; instead, the future 
384 brush hairs are always specified at the maximum density allowed by lateral inhibition. Independent evolution of this highly derived spatial pattern in multiple lineages suggests that similar selective pressures may elicit not only similar structures, but also similar changes in the underlying developmental mechanisms.

\section{A hierarchy of convergence, from structures to genes} birds, fish and dolphins, or the vertebrate and cephalopod eyes are textbook clichés. Less obvious but equally striking examples of convergent forms shaped by a common function

394 include the asymmetrical ears of owls (Nishikawa, 2002), Mullerian mimicry in butterflies

395 (Brower, 1994; Naisbit et al., 2003), trophic morphology in cichlid fishes (Ruber and Adams, 396 2001), and many others (Moore and Willmer, 1997). A fundamental question raised by the

397 widespread occurrence of convergent traits is to what extent phenotypic convergence reflects an underlying similarity of the molecular and cellular mechanisms that control individual development.

The mechanisms of convergence can be viewed in either genetic or developmental

401 terms. From the genetic standpoint, convergent phenotypes are controlled by the same 402 mechanism if they are the result of changes in the same loci ("genetic convergence") 403 (Gompel and Prud'homme, 2009; Martin and Orgogozo, 2013). Alternatively, convergent 404 changes may be considered to share a similar mechanism if they are produced by the same 405 changes in development, regardless of the ultimate genetic causes ("developmental 406 convergence") (Wake, 1991; Wake et al., 2011; Wray, 2002). We can describe convergence 407 in hierarchical terms by applying three increasingly stringent criteria: phenotypic, 408 developmental, and genetic. Phenotypic convergence can occur without developmental 409 convergence: for example, the disproportionally elongated bodies of burrowing 410 salamanders can be caused either by an increase in the number of vertebrae, or by 411 increased length of the individual vertebrae - a superficial phenotypic resemblance 412 produced by entirely different developmental mechanisms (Parra-Olea and Wake, 2001). 413 Similarly, larval abdominal prolegs of butterflies and sawflies, while superficially similar 414 and playing similar roles in locomotion, develop from non-homologous leg segments 
415 (Suzuki and Palopoli, 2001). In D. melanogaster, latitudinal clines in wing size have evolved 416 on several continents, but the differences in wing size are due largely to differences in cell 417 number in some populations, while in other populations differences in the size of 418 individual cells make a larger contribution (James et al., 1997; Zwaan et al., 2000).

419 Developmental convergence, in turn, does not necessarily reflect genetic 420 convergence. In Drosophila, similar color patterns can evolve in different species through 421 changes at different loci (Signor et al., 2016; Wittkopp et al., 2003b; Yassin et al., 2016), but 422 in the end all of these genetic changes are translated into adult phenotypes through the 423 same set of enzymatic reactions in the catecholamine metabolism pathway (Kronforst et al., 424 2012; Wittkopp and Beldade, 2009; Wittkopp et al., 2003a), presenting an example of 425 developmental convergence in the absence of genetic convergence. In other cases, the 426 evolution of similar phenotypes in distantly related species is clearly caused by 427 independent changes in the same genes - as, for example, in the loss of larval cuticular 428 hairs through regulatory mutations in the shavenbaby gene in two Drosophila species 429 separated by $>40$ million years (Sucena et al., 2003), or in the evolution of mimetic wing 430 color patterns in different species of Heliconius butterflies through parallel changes in the 431 optix and WntA genes (Gallant et al., 2014; Hines et al., 2011; Martin et al., 2012; Reed et al., 432 2011; Supple et al., 2013).

433 Going even deeper from the genetic to the molecular level, we can ask whether 434 recurrent involvement of the same gene in multiple instances of convergent evolution 435 reflects repeated appearance of the same mutations, or whether different mutations can 436 alter the function of the causative gene in similar ways, leading to the evolution of similar 437 phenotypes. Again, we can find examples in support of either scenario. A variety of 438 proteins have evolved similar amino acid residues and active sites repeatedly in different 439 taxa (Gasparini et al., 1998; Hill et al., 2019; Kriener et al., 2000; Lopreato et al., 2001; 440 Yokoyama, 2002). Although non-coding DNA sequences are clearly less constrained in 441 their function than proteins, similar regulatory mutations can nevertheless appear and be 442 fixed independently in different populations or species in response to similar selective 443 pressures (Chan et al., 2010; Loehlin et al., 2019; Xie et al., 2019). Conversely, mutations 444 that affect different amino acids, or different cis-regulatory elements, can produce similar 
445 phenotypic outcomes in different populations or species (Gross et al., 2009; Kingsley et al., 446 2009; Manceau et al., 2010; Protas et al., 2006; Rosenblum et al., 2009; Yassin et al., 2016).

447 The sex brush represents a clear case of developmental convergence, but the genetic 448 control of its development remains to be determined. Specification and positioning of the 449 sex brush are likely to involve the HOX gene Scr and the sex determination gene doublesex 450 (Rice et al., 2018; Tanaka et al., 2011). However, the identity of the downstream genes that 451 translate the regulatory information provided by $d s x$ and Scr into the final 3-dimensional 452 structure is unknown. In principle, these genes need not be the same in different lineages. 453 Future work may show whether the convergence we observe at the level of cell behavior 454 extends to the genetic and molecular level.

Convergent innovation and the failure to innovate

The evolution of similar structures in response to similar functional demands is perhaps not surprising; should we instead be surprised when organisms faced with similar demands fail to evolve convergent phenotypes (Blount et al., 2018)? Males grasp female abdomen with their front legs in many Drosophila species, including those that primitively lack any male-specific leg ornaments (Massey et al., 2019; Spieth, 1952). Why don't all Drosophila species evolve sex combs, brushes, or other grasping structures? Development does not provide any clues. At the level of cell behavior, both the ancestral/female condition (cell migration that produces tightly packed bristle rows from sparsely spaced precursors) and the derived/male condition (specification of bristle precursors at the maximum density permitted by lateral inhibition) are the same in all lineages where the sex brush is present. There is no a priori reason to think that the transition between these modes of development is easier in some species than others. males of different species use their sex brushes in at least superficially similar ways, we 473 responses to male grasping, the evolution of specialized leg structures in males may not be 474 universally favored. This may also explain why both the sex brushes and the sex combs 475 (Kopp, 2011) have been secondarily lost multiple times. Moreover, it is difficult to know 
476 whether the female preferences observed today are the same as they were in the distant past when the male-specific structures evolved (Watts et al., 2019).

Alternatively, the origin of a new trait such as the leg brush may require such an unlikely series of genetic changes that it may often fail to occur even in response to strong selective pressure. For example, it is possible that while a single mutation is sufficient to modify or eliminate an existing morphological structure, the origin of a new structure may require simultaneous changes in multiple genes. From the population-genetic perspective, this would mean that functionally novel and positively interacting alleles at multiple loci must segregate in the same population at the same time in order for selection in favor of a new structure to be effective. Naturally, this would greatly reduce the probability of evolutionary innovations compared to other types of phenotypic change. This is of course pure speculation; we do not know why convergent innovations evolve in some lineages but fail to evolve in others. We hope that research models where both the functional roles and the genetic basis of novel traits can be studied in parallel will shed some light on this

\section{Acknowledgements}

We thank the US Drosophila species stock center, Ehime University Drosophila stock center, 495 J.-R. David, S. Prigent, and M. Watada for Drosophila strains and specimens; Developmental 496 Studies Hybridoma Bank for antibodies; A. Comeault, A. Gloss, M. Lang, D. Matute, D. Miller,

497 V. Orgogozo, and N. Whiteman for genome assemblies; M. Toda for advice on Zaprionus phylogeny; G. Rice for D. immigrans images; and A. Yassin for comments on the manuscript.

499 We also thank the MCB Light Microscopy Imaging Facility, Department of Cell Biology and 500 Human Anatomy EM Lab, and Materials Science and Engineering AMCaT Lab at UC Davis

501 for equipment and imaging assistance, and Gwyneth Card and W. Ryan Williamson for use 502 of the Photron camera. The Olympus FV1000 confocal used in this study was purchased 503 using NIH Shared Instrumentation Grant 1S10RR019266-01. AK and OB are grateful to N. 504 Gompel for allowing some of this work to be conducted in his lab while on a sabbatical visit, 505 and to members of the Gompel lab for treating them as their labmates. This work was 
bioRxiv preprint doi: https://doi.org/10.1101/786764; this version posted September 30, 2019. The copyright holder for this preprint (which was not certified by peer review) is the author/funder, who has granted bioRxiv a license to display the preprint in perpetuity. It is made available under aCC-BY 4.0 International license.

506 supported by NIH grant 5R35GM122592 to AK and by funds from Ludwig-Maximilians-

507 Universität München to Nicolas Gompel. 
510 The immigrans species group and the wider immigrans-tripunctata radiation have long 511 played a pivotal role in Drosophila systematics (Throckmorton, 1975; Yassin, 2013).

512 However, the composition of the immigrans group has not been entirely clear. Historically,

513 this group was proposed to include five subgroups: immigrans, hypocausta, nasuta, 514 quadrilineata, and curviceps (Huang et al., 2002; Zhang and Toda, 1988, 1992; Zhang et al., 515 1995). Recent studies have shown, however, that both the hypocausta and the immigrans 516 subgroups are likely polyphyletic, as some species assigned to these subgroups are actually 517 closer to the nasuta subgroup (Da Lage et al., 2007; Katoh et al., 2007; Rice et al., 2018). 518 The quadrilineata and curviceps subgroups have been the source of even greater 519 complications. Previous phylogenetic studies have provided evidence against a sister520 group relationship between D. quadrilineata and the rest of the immigrans species group 521 (Katoh et al., 2007; Morales-Hojas and Vieira, 2012; Yassin, 2013). Moreover, D. annulipes, 522 traditionally assigned to the quadrilineata subgroup (Lin and Tseng, 1973), was found to be 523 distantly related to D. quadrilineata, and closer to the virilis-repleta radiation (Katoh et al., 524 2007). The phylogeny of Huang et al (Huang et al., 2002) showed a close relationship 525 between D. annulipes and the clade composed of D. curviceps and D. oritisa, another species 526 assigned to the curviceps subgroup. Morales-Hojas and Vieira (Morales-Hojas and Vieira, 527 2012) confirmed the distant relationship between D. annulipes and D. quadrilineata, as well 528 as between D. annulipes and the immigrans species group sensu stricto. Yassin (Yassin, 529 2013) pointed out important differences between D. quadrilineata and the curviceps 530 subgroup and the immigrans group s.s. Finally, Pradhan et al (Pradhan et al., 2015) 531 removed the curviceps subgroup from the immigrans species group, elevating it to the 532 status of a separate species group.

533 Our analysis, based on a larger amount of sequence data than previous studies, 534 confirms these observations, namely that (1) D. quadrilineata is not closely related either to 535 the immigrans species group s.s. or to D. annulipes, (2) D. curviceps is not closely related to 536 the immigrans species group s.s., and (3) D. annulipes is related to D. curviceps. Based on 537 these results, we support the conclusions on other authors (Katoh et al., 2007; Pradhan et 538 al., 2015; Yassin, 2013) that the definition of the immigrans species group should be 
539 restricted to the immigrans, hypocausta, and nasuta subgroups. Further work, with a more

540 extensive sampling of the immigrans group s.S., is needed to revise its internal taxonomy

541 and re-establish monophyletic subgroups. Similarly, better taxon sampling will be needed

542 to determine whether $D$. annulipes could be reassigned to the curviceps species group

543 (Pradhan et al., 2015), or whether it is possible to establish a monophyletic quadrilineata

544 species group.

545 


\section{References}

Atallah, J., Liu, N.H., Dennis, P., Hon, A., Godt, D., and Larsen, E.W. (2009). Cell dynamics and developmental bias in the ontogeny of a complex sexually dimorphic trait in Drosophila melanogaster. Evol Dev 11, 191-204.

552 Blount, Z.D., Lenski, R.E., and Losos, J.B. (2018). Contingency and determinism in evolution: Replaying life's tape. Science 362. Brower, A.V. (1994). Rapid morphological radiation and convergence among races of the butterfly Heliconius erato inferred from patterns of mitochondrial DNA evolution. Proc Natl Acad Sci U S A 91, 6491-6495. Chan, Y.F., Marks, M.E., Jones, F.C., Villarreal, G., Jr., Shapiro, M.D., Brady, S.D., Southwick, A.M., Absher, D.M., Grimwood, J., Schmutz, J., et al. (2010). Adaptive evolution of pelvic reduction in sticklebacks by recurrent deletion of a Pitx1 enhancer. Science 327, 302-305. Da Lage, J.-L., Kergoat, G.J., Maczkowiak, F., Silvain, J.-F., Cariou, M.-L., and Lachaise, D. (2007). A phylogeny of Drosophilidae using the Amyrel gene: questioning the Drosophila melanogaster species group boundaries. J Zool Syst Evol Res 45, 47-63. polymorphic asymmetry in a new empidine dance fly (Diptera: Empididae). Biology letters 7,11-14.

Eberhard, W.G. (2001). The functional morphology of species-specific clasping structures on the front legs of male Archisepsis and Palaeosepsis flies (Diptera, Sepsidae). Zoological Journal of the Linnean Society 133, 335-368.

568 Edgar, R.C. (2004). MUSCLE: a multiple sequence alignment method with reduced time and space complexity. BMC Bioinformatics 5, 113. Smith, G.E., Evans, B., Reed, R.D., et al. (2014). Ancient homology underlies adaptive mimetic diversity across butterflies. Nature communications 5, 4817. C.C., Rowan, E.G., Harvey, A.L., and Menez, A. (1998). Delineation of the functional site of alpha-dendrotoxin. The functional topographies of dendrotoxins are different but share a conserved core with those of other Kv1 potassium channel-blocking toxins. J Biol Chem 273, 25393-25403.

578 Gompel, N., and Prud'homme, B. (2009). The causes of repeated genetic evolution. Dev Biol $579332,36-47$.

580 Gross, J.B., Borowsky, R., and Tabin, C.J. (2009). A novel role for Mc1r in the parallel evolution of depigmentation in independent populations of the cavefish Astyanax mexicanus. PLoS Genet 5, e1000326. New algorithms and methods to estimate maximum-likelihood phylogenies: assessing the performance of PhyML 3.0. Syst Biol 59, 307-321.

Gupta, J.P. (1972). D. orissaensis, a new species of Drosophila from Orissa, India. Oriental Insects 6, 561-563.

590

Hardy, D.E. (1965). Diptera: Cyclorrhapha II, series Schizophora, section Acalypterae I, family Drosophilidae. . In Insects of Hawaii, E.C. Zimmerman, ed. (Honolulu: University of Hawaii Press). 
591 Hill, J., Enbody, E.D., Pettersson, M.E., Sprehn, C.G., Bekkevold, D., Folkvord, A., Laikre, L., 592 Kleinau, G., Scheerer, P., and Andersson, L. (2019). Recurrent convergent evolution at amino acid residue 261 in fish rhodopsin. Proc Natl Acad Sci U S A 116, 18473-18478. Hines, H.M., Counterman, B.A., Papa, R., Albuquerque de Moura, P., Cardoso, M.Z., Linares, M., Mallet, J., Reed, R.D., Jiggins, C.D., Kronforst, M.R., et al. (2011). Wing patterning gene redefines the mimetic history of Heliconius butterflies. Proc Natl Acad Sci U S A 108, 1966619671. Hsu, T.C. (1943). Chromosomes of Drosophila repletoides. Kwangsi Agric 4, 155-160. Huang, J., Hao, L., Liu, S., Li, L., Zhang, W.-X., and Dai, Z.-H. (2002). Phylogenetic position of Chinese endemic Drosophila curviceps species subgroup in the Drosophila immigrans group. Acta Genetica Sinica 29, 417-423. Huber, B.A., Sinclair, B.J., and Schmitt, M. (2007). The evolution of asymmetric genitalia in spiders and insects. Biol Rev 82, 647-698.

604 Ingram, K.K., Laamanen, T., Puniamoorthy, N., and Meier, R. (2008). Lack of morphological coevolution between male forelegs and female wings in Themira (Sepsidae : Diptera : Insecta). Biological Journal of the Linnean Society 93, 227-238. Izumitani, H.F., Kusaka, Y., Koshikawa, S., Toda, M.J., and Katoh, T. (2016). Phylogeography of the Subgenus Drosophila (Diptera: Drosophilidae): Evolutionary History of Faunal Divergence between the Old and the New Worlds. PLoS ONE 11, e0160051. James, A.C., Azevedo, R.B., and Partridge, L. (1997). Genetic and environmental responses to temperature of Drosophila melanogaster from a latitudinal cline. Genetics 146, 881-890. Katoh, T., Nakaya, D., Tamura, K., and Aotsuka, T. (2007). Phylogeny of the Drosophila immigrans species group (Diptera: Drosophilidae) based on Adh and Gpdh sequences. Zoolog Sci 24, 913-921. Katoh, T.K., Zhang, G., Toda, M.J., Zhang, W.X., and Gao, J.J. (2018). The Lordiphosa denticeps species group (Diptera: Drosophilidae) in China, with redescriptions of four known species and descriptions of nine new species. Zootaxa 4471, 37-75. A., Markowitz, S., Duran, C., et al. (2012). Geneious Basic: an integrated and extendable desktop software platform for the organization and analysis of sequence data. Bioinformatics 28, 1647-1649.

624 Kingsley, E.P., Manceau, M., Wiley, C.D., and Hoekstra, H.E. (2009). Melanism in peromyscus is caused by independent mutations in agouti. PLoS ONE 4, e6435. Kopp, A. (2011). Drosophila Sex Combs as a Model of Evolutionary Innovations. Evol Dev 13, 504-522.

Kriener, K., O'HUigin, C., Tichy, H., and Klein, J. (2000). Convergent evolution of major histocompatibility complex molecules in humans and New World monkeys. Immunogenetics 51, 169-178. Rosenblum, E.B., Schneider, C.J., and Hoekstra, H.E. (2012). Unraveling the thread of nature's tapestry: the genetics of diversity and convergence in animal pigmentation. 
Lanfear, R., Calcott, B., Ho, S.Y., and Guindon, S. (2012). Partitionfinder: combined selection of partitioning schemes and substitution models for phylogenetic analyses. Mol Biol Evol 29, 1695-1701. Lanfear, R., Frandsen, P.B., Wright, A.M., Senfeld, T., and Calcott, B. (2017). PartitionFinder 2: New Methods for Selecting Partitioned Models of Evolution for Molecular and Morphological Phylogenetic Analyses. Mol Biol Evol 34, 772-773. Lin, F.-J., and Tseng, H.-C. (1973). The Drosophila immigrans species group in Taiwan with descriptions of five new species. Bull Inst Zool, Academia Sinica 12, 13-26. Loehlin, D.W., Ames, J.R., Vaccaro, K., and Carroll, S.B. (2019). A major role for noncoding regulatory mutations in the evolution of enzyme activity. Proc Natl Acad Sci U S A 116, 12383-12389. (2001). Evolution and divergence of sodium channel genes in vertebrates. Proc Natl Acad Sci U S A 98, 7588-7592. Mainx, F. (1958). Zaprionus bogoriensis spec. nov.,eine neue Drosophilide aus Java. Zoologischer Anzeiger 161, 126-130. Convergence in pigmentation at multiple levels: mutations, genes and function. Philos T R Soc B 365, 2439-2450.

Martin, A., and Orgogozo, V. (2013). The Loci of repeated evolution: a catalog of genetic hotspots of phenotypic variation. Evolution 67, 1235-1250.

Martin, A., Papa, R., Nadeau, N.J., Hill, R.I., Counterman, B.A., Halder, G., Jiggins, C.D., Kronforst, M.R., Long, A.D., McMillan, W.O., et al. (2012). Diversification of complex butterfly wing patterns by repeated regulatory evolution of a Wnt ligand. Proc Natl Acad Sci U S A 109, 12632-12637. Massey, J.H., Chung, D., Siwanowicz, I., Stern, D.L., and Wittkopp, P. (2019). The yellow gene influences Drosophila male mating 1 success through sex comb melanizatio. eLife in press. McAlpine, J.F. (1981). Morphology and terminology - adults. In Manual of Nearctic Diptera, J.F. McAlpine, B.V. Peterson, G.E. Shewell, H.J. Teskey, J.R. Vockeroth, and D.M. Wood, eds. (Ottawa: Research Branch, Agriculture Canada), pp. 9--63. Moore, J., and Willmer, P. (1997). Convergent evolution in invertebrates. Biol Rev Camb Philos Soc 72, 1-60.

Morales-Hojas, R., and Vieira, J. (2012). Phylogenetic patterns of geographical and ecological diversification in the subgenus Drosophila. PLoS ONE 7, e49552. Naisbit, R.E., Jiggins, C.D., and Mallet, J. (2003). Mimicry: developmental genes that contribute to speciation. Evol Dev 5, 269-280.

672 Nishikawa, K.C. (2002). Evolutionary convergence in nervous systems: insights from comparative phylogenetic studies. Brain Behav Evol 59, 240-249.

Okada, T. (1964). Drosophilidae (Diptera) of Southeast Asia collected by the Thai-Japanese Biological Expedition 1961-62. In Nature and Life in Southeast Asia, T.a.U. Kira, T., ed. (Kyoto: Fauna and Flora Research Society), pp. 439-466. Okada, T., and Carson, H.L. (1983). The genera Phorticella Duda and Zaprionus Coquillett (Diptera, Drosophilidae) of the Oriental region and New Guinea. Kontyu 51, 539-553.

Parra-Olea, G., and Wake, D.B. (2001). Extreme morphological and ecological homoplasy in tropical salamanders. Proc Natl Acad Sci U S A 98, 7888-7891. 
680 Pradhan, S., Sati, P.C., Fartyal., R.S., Chatterjee, R.N., Sarswat, M., Kandpal, M.C., and Singh, B.K. (2015). Drosophila curviceps Species-Group (Diptera: Drosophilidae) from India, with Description of a New Species and Redescription of a Known Species. Proceedings of the Zoological Society 68, 178-183.

684 Protas, M.E., Hersey, C., Kochanek, D., Zhou, Y., Wilkens, H., Jeffery, W.R., Zon, L.I., Borowsky, 685 R., and Tabin, C.J. (2006). Genetic analysis of cavefish reveals molecular convergence in the evolution of albinism. Nat Genet 38, 107-111. Chamberlain, N.L., Kronforst, M.R., Chen, R., et al. (2011). optix drives the repeated convergent evolution of butterfly wing pattern mimicry. Science 333, 1137-1141. Rice, G., Barmina, O., Hu, K., and Kopp, A. (2018). Evolving doublesex expression correlates with the origin and diversification of male sexual ornaments in the Drosophila immigrans 692 species group. Evol Dev 20, 78-88.

693 Ronquist, F., Teslenko, M., van der Mark, P., Ayres, D.L., Darling, A., Hohna, S., Larget, B., Liu, L., Suchard, M.A., and Huelsenbeck, J.P. (2012). MrBayes 3.2: efficient Bayesian phylogenetic inference and model choice across a large model space. Syst Biol 61, 539-542. Rosenblum, E.B., Rompler, H., Schoneberg, T., and Hoekstra, H.E. (2009). Molecular and functional basis of phenotypic convergence in white lizards at White Sands. Proc Natl Acad Sci U S A.

Ruber, L., and Adams, D.C. (2001). Evolutionary convergence of body shape and trophic morphology in cichlids from Lake Tanganyika. J Evol Biol 13, 325. Russo, C.A., Mello, B., Frazao, A., and Voloch, C.M. (2013). Phylogenetic analysis and a time tree for a large drosophilid data set (Diptera: Drosophilidae). Zoological Journal of the Linnean Society 169, 765-775.

Signor, S.A., Liu, Y., Rebeiz, M., and Kopp, A. (2016). Genetic Convergence in the Evolution of Male-Specific Color Patterns in Drosophila. Curr Biol 26, 2423-2433. Simpson, P. (1990). Lateral inhibition and the development of the sensory bristles of the adult peripheral nervous system of Drosophila. Development 109, 509-519. Sivinski, J. (1997). Ornaments in the Diptera. Florida Entomologist 80, 142-164. Spieth, H.T. (1952). Mating behavior within the genus Drosophila (Diptera). Bulletin of the American Museum of Natural History 99, 395-474. Stark, J.B., and O'Grady, P.M. (2009). Morphological variation in the forelegs of the Hawaiian Drosophilidae. I. The AMC clade. J Morphol. Sucena, E., Delon, I., Jones, I., Payre, F., and Stern, D.L. (2003). Regulatory evolution of shavenbaby/ovo underlies multiple cases of morphological parallelism. Nature 424, 935938.

720 Suzuki, Y., and Palopoli, M.F. (2001). Evolution of insect abdominal appendages: are prolegs Supple, M.A., Hines, H.M., Dasmahapatra, K.K., Lewis, J.J., Nielsen, D.M., Lavoie, C., Ray, D.A., Salazar, C., McMillan, W.O., and Counterman, B.A. (2013). Genomic architecture of adaptive color pattern divergence and convergence in Heliconius butterflies. Genome Res 23, 12481257. homologous or convergent traits? Development Genes and Evolution 211, 486-492. Tan, C.C., Hsu, T.C., and Sheng, T.C. (1949). Known drosophila species in China with descriptions of twelve new species. In Studies in the genetics of Drosophila VI Articles on genetics, cytology, and taxonomy, J.T. Patterson, ed. (Austin, TX: University of Texas Publications), pp. 196-206. 
Tanaka, K., Barmina, O., and Kopp, A. (2009). Distinct developmental mechanisms underlie the evolutionary diversification of Drosophila sex combs. Proceedings of the National Academy of Sciences 106, 4764-4769. Sex-Specific Traits through Changes in HOX-Dependent doublesex Expression. PLoS Biol 9, 731 e1001131. Throckmorton, L.H. (1975). The phylogeny, ecology, and geography of Drosophila. In Handbook of Genetics, R.C. King, ed. (Plenum Press: Plenum Press), pp. 421-469. Tsacas, L. (2002). Le nouveau complexe africain Drosophila loiciana et l'espèce apparentée D. matileana n. sp. (Diptera : Drosophilidae). Ann Soc entomol Fr 38, 57-70. Tsacas, L., and Chassagnard, M.-T. (2000). Drosophila loiciana, nouvelle espèce africaine et redescription de son epèce affine D. pruinosa Dudas (Diptera, Drosophilidae). Revue française d'entomologie 22, 213-222. Tsacas, L., and Chassagnard, M.T. (1990). The Species of the Genus Zaprionus with the Fore Femora Bearing Spines (Diptera, Drosophilidae). Annales De La Societe Entomologique De France 26, 461-487.

Wake, D.B. (1991). Homoplasy - the Result of Natural-Selection, or Evidence of Design Limitations. American Naturalist 138, 543-567.

Wake, D.B., Wake, M.H., and Specht, C.D. (2011). Homoplasy: from detecting pattern to determining process and mechanism of evolution. Science 331, 1032-1035. Watts, J.C., Flynn, A., Tenhumberg, B., and Hebets, E.A. (2019). Contemporary sexual selection does not explain variation in male display traits among populations. Evolution. Wheeler, M.R. (1981). The Drosophilidae. In The Genetics and Biology of Drosophila, M. Ashburner, H.L. Carson, and J.N. Thompson, eds. (Academic Press), pp. 1-97.

Wittkopp, P.J., and Beldade, P. (2009). Development and evolution of insect pigmentation: genetic mechanisms and the potential consequences of pleiotropy. Semin Cell Dev Biol 20, 65-71.

Wittkopp, P.J., Carroll, S.B., and Kopp, A. (2003a). Evolution in black and white: genetic control of pigment patterns in Drosophila. Trends Genet 19, 495-504.

755

756

757 Wittkopp, P.J., Williams, B.L., Selegue, J.E., and Carroll, S.B. (2003b). Drosophila pigmentation evolution: divergent genotypes underlying convergent phenotypes. Proc Natl Acad Sci U S A 100, 1808-1813.

Wray, G.A. (2002). Do convergent developmental mechanisms underlie convergent phenotypes? Brain Behav Evolut 59, 327-336. Wynn, S., and Toda, M.J. (1988). Drosophilidae (Diptera) in Burma. IV. The genus Zaprionus. Kontyu 56, 843-851.

Xie, K.T., Wang, G., Thompson, A.C., Wucherpfennig, J.I., Reimchen, T.E., MacColl, A.D.C., Schluter, D., Bell, M.A., Vasquez, K.M., and Kingsley, D.M. (2019). DNA fragility in the parallel evolution of pelvic reduction in stickleback fish. Science 363, 81-84.

Yassin, A. (2007). A revision of the tumiditarsus group of the subgenus Drosophila and its relation to the genus Zaprionus. Drosophila Information Service 90, 20-22.

Yassin, A. (2013). Phylogenetic classification of the Drosophilidae Rondani (Diptera): the role of morphology in the postgenomic era. Systematic Entomology 38, 349-364. and David, J.R. (2008). Grafting the molecular phylogenetic tree with morphological 
771 branches to reconstruct the evolutionary history of the genus Zaprionus (Diptera: 772 Drosophilidae). Mol Phylogenet Evol 47, 903-915.

773 Yassin, A., Da Lage, J.L., David, J.R., Kondo, M., Madi-Ravazzi, L., Prigent, S.R., and Toda, M.J. 774 (2010). Polyphyly of the Zaprionus genus group (Diptera: Drosophilidae). Mol Phylogenet 775 Evol 55, 335-339.

776 Yassin, A., and David, J.R. (2010). Revision of the Afrotropical species of Zaprionus (Diptera, 777 Drosophilidae), with descriptions of two new species and notes on internal reproductive 778 structures and immature stages. ZooKeys 51, 33-72.

779 Yassin, A., Delaney, E.K., Reddiex, A.J., Seher, T.D., Bastide, H., Appleton, N.C., Lack, J.B., David, 780 J.R., Chenoweth, S.F., Pool, J.E., et al. (2016). The pdm3 Locus Is a Hotspot for Recurrent 781 Evolution of Female-Limited Color Dimorphism in Drosophila. Curr Biol 26, 2412-2422.

782 Yokoyama, S. (2002). Molecular evolution of color vision in vertebrates. Gene 300, 69-78.

783 Zhang, W.-X., and Toda, M.J. (1988). The Drosophila immigrans species-group of the 784 subgenus Drosophila (Diptera: Drosophilidae) in Yunnan, China. Zool Sci 5, 1095-1103.

785 Zhang, W.-X., and Toda, M.J. (1992). A new species-subgroup of the Drosophila immigrans 786 species-group (Diptera, Drosophilidae), with descriptions of two new species from China 787 and revision of taxonomic terminology. Jpn J Genet 60, 839-850.

788 Zhang, W.-X., Toda, M.J., and Watabe, H. (1995). Fourteen new species of the Drosophila 789 (Drosophila) immigrans species group from the Oriental region. Jpn J Genet 63, 25-51.

790 Zwaan, B.J., Azevedo, R.B., James, A.C., Van 't Land, J., and Partridge, L. (2000). Cellular basis 791 of wing size variation in Drosophila melanogaster: a comparison of latitudinal clines on two 792 continents. Heredity 84 ( Pt 3), 338-347.

793 
797 Brightfield images of the first and second tarsal segments (ta1 and ta2) of the prothoracic 798 leg in males of six species. (B, D, F, H, J, L) SEM images of the ta1 sex brush. A-B) D.

799 pruinosa. A) The brush occupies the distal $\sim 80 \%$ of ta1, replacing most of the transverse 800 bristle rows (TBRs, shown by brackets in this and other panels), which in females covers 801 the entire anterior-ventral surface. The ta1 segment is slightly widened at the distal end.

802 B) The tips of brush hairs are flattened, pointed, and form hooks that curve toward the base 803 of the leg (see inset). C-D) D. immigrans. C) The brush covers the distal $\sim 60 \%$ of ta1 and 804 most of ta2. The shape of the segments is not modified. D) Similar to D. pruinosa, the brush 805 hairs are flattened, pointed, and form proximally curving hooks at the tips (inset). E-F) $D$. 806 repletoides. E) The brush covers $\sim 70 \%$ of ta1 and most of ta 2 . Both segments are 807 shortened and have a bulbous shape. F) The tips of brush hairs are flattened but thick and 808 blunt. They form hooks that curve away from the leg base (inset). G-H) Z. tuberculatus. G) 809 The brush covers the distal $\sim 60 \%$ of ta1. H) The tips of brush hairs curve distally and have 810 a pointed paddle-like shape with a slight depression (inset). I-J) Z. vittiger. K-L) Z. 811 bogoriensis. These species have distally curving tips of brush hairs, similar to $Z$. 812 tuberculatus.

814 Figure 2. Sex brushes evolved independently at least three times. Species and clades 815 with male sex brushes are highlighted in blue. A) Bayesian phylogeny of the species 816 represented in this study, based on the combined dataset. Numbers at each node indicate 817 the posterior probabilities of the respective taxon bipartitions. B) Bayesian phylogeny 818 based on the same dataset but excluding D. quadrilineata. Posterior probabilities of nodes 819 A-E in different analyses can be found in Supplement Table 3.

821 Figure 3. Sex brush development shows strong similarities across species. 822 Developing brush hair cells were visualized by immunostaining for membrane markers E823 cadherin (DE-cad) or Armadillo (Arm). For each species, the upper panels show the 824 confocal projections of ta1 segment (A-D, G-H) or both ta1 and ta2 (E-F). The bottom 
825 panels ( $\left.\mathrm{A}^{\prime}-\mathrm{H}^{\prime}\right)$ show close-up views. For each species, early developmental stages are

826 shown on the left and later stages on the right. A-B') D. pruinosa, 27 and 42 hrs after

827 pupariation (AP). C-D') D. immigrans, 24 and 43 hrs AP. E-F') D. repletoides, 28 and 43 hrs

828 AP. G-H') Z. tuberculatus, 34 and 48 hrs AP. Hair progenitor cells can be distinguished from

829 epithelial cells by a ring of bright staining with a dense punctum in the middle. In all four

830 species, each hair cell is surrounded by 4-6 epithelial cells (blue dots), so that neighboring

831 hair cells are separated from each other by 1-2 cells, at both the early and the late stages.

832 The proximal TBRs (square brackets) form by expelling the intervening epithelial cells,

833 with the bristle progenitor cells migrating closer together to make straight rows (Tanaka et

834 al 2009) (e.g., compare A vs B, and G vs H). In contrast, no cell rearrangement is observed

835 in the brush.

836

837 Supplement Figure 1. Strict consensus of 11 trees with the cumulative posterior

838 probability of $95 \%$ for the complete taxon sample, labeled as in Figure 1. Numbers at each

839 node indicate the posterior probabilities of the respective taxon bipartitions.

841 Supplement Figure 2. Strict consensus of 11 trees with the cumulative posterior 842 probability of $99 \%$ for the taxon sample without D. quadrilineata.

844 Supplement Figure 3. Bayesian phylogenetic tree for the complete taxon sample, with the 845 dataset partitioned by gene and codon.

847 Supplement Figure 4. Phylogenetic tree for the taxon sample without D. quadrilineata, 848 with the dataset partitioned by gene and codon. 

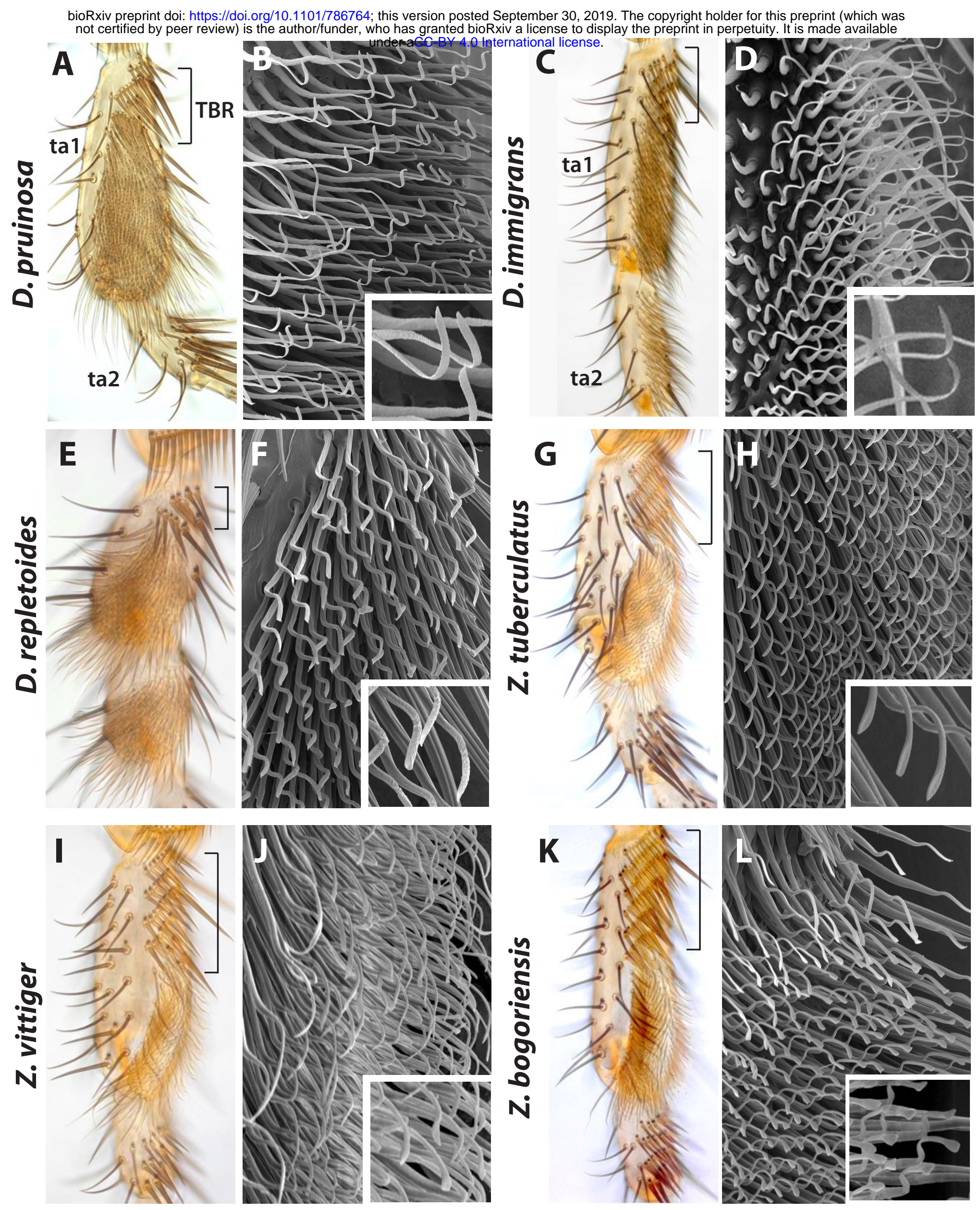

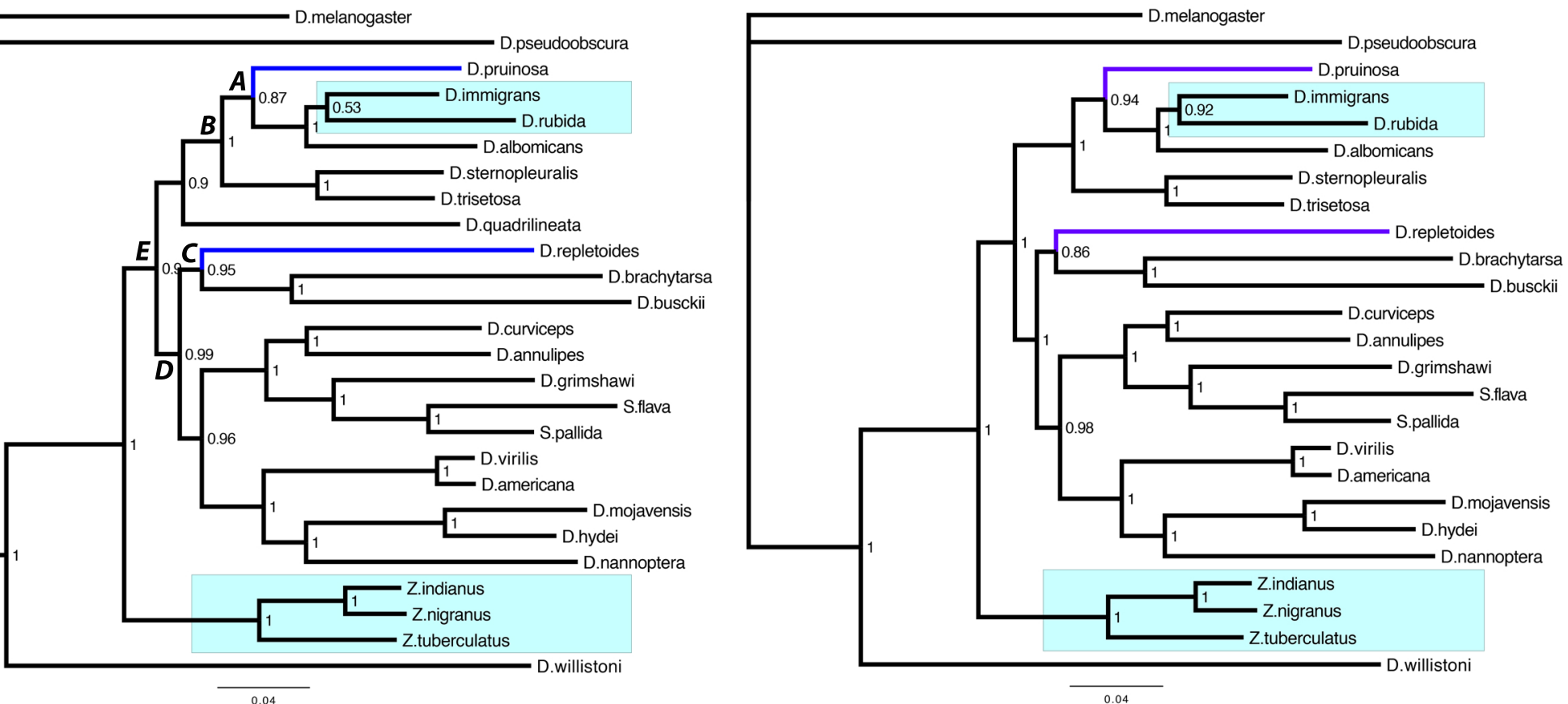
bioRxiv preprint doi: https://doi.org/10.1101/786764; this version posted September 30, 2019. The copyright holder for this preprint (which was

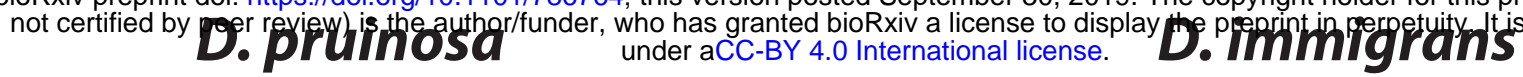

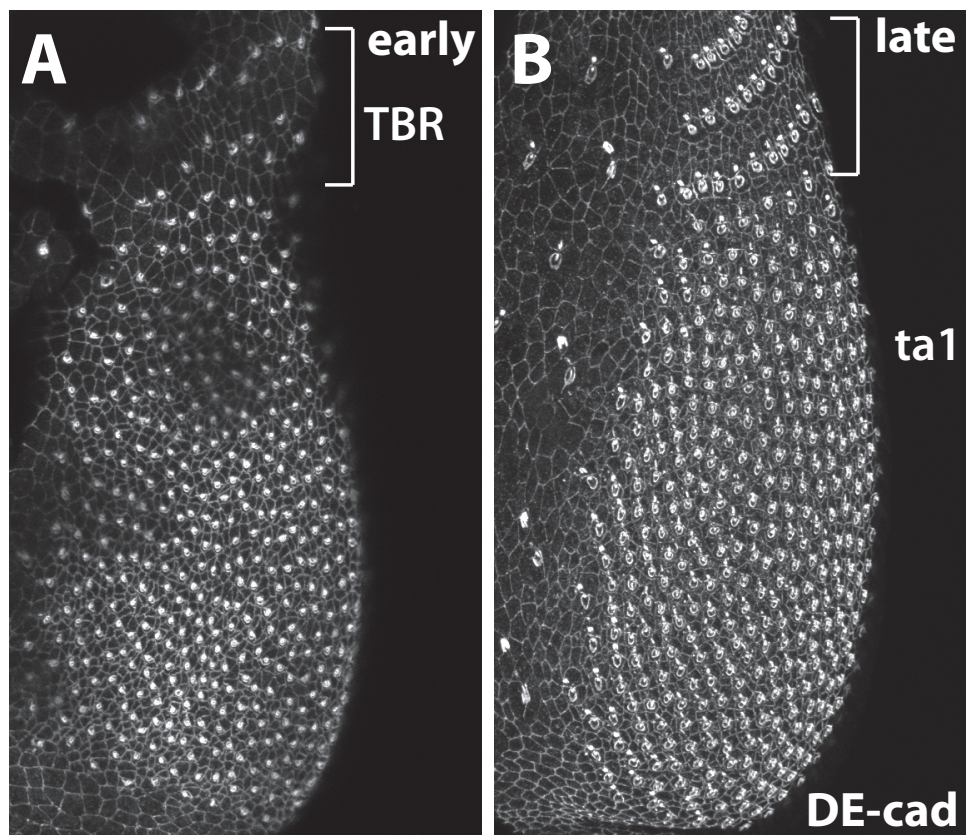

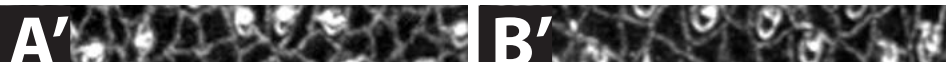

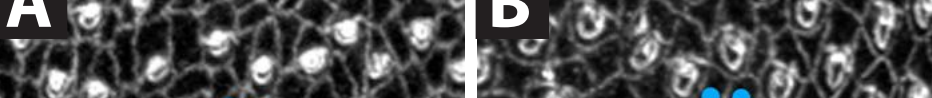

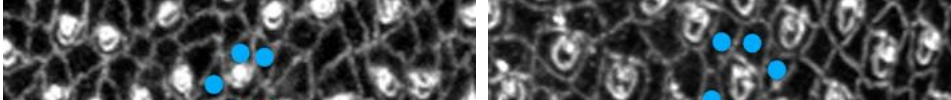

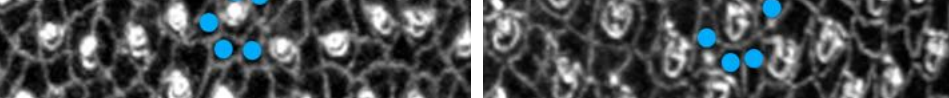

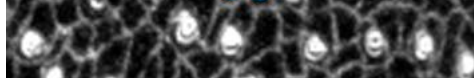

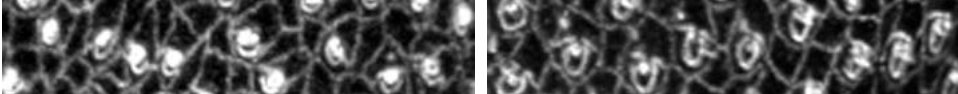

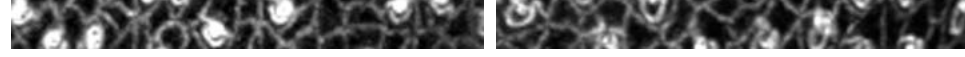

\section{D. repletoides}

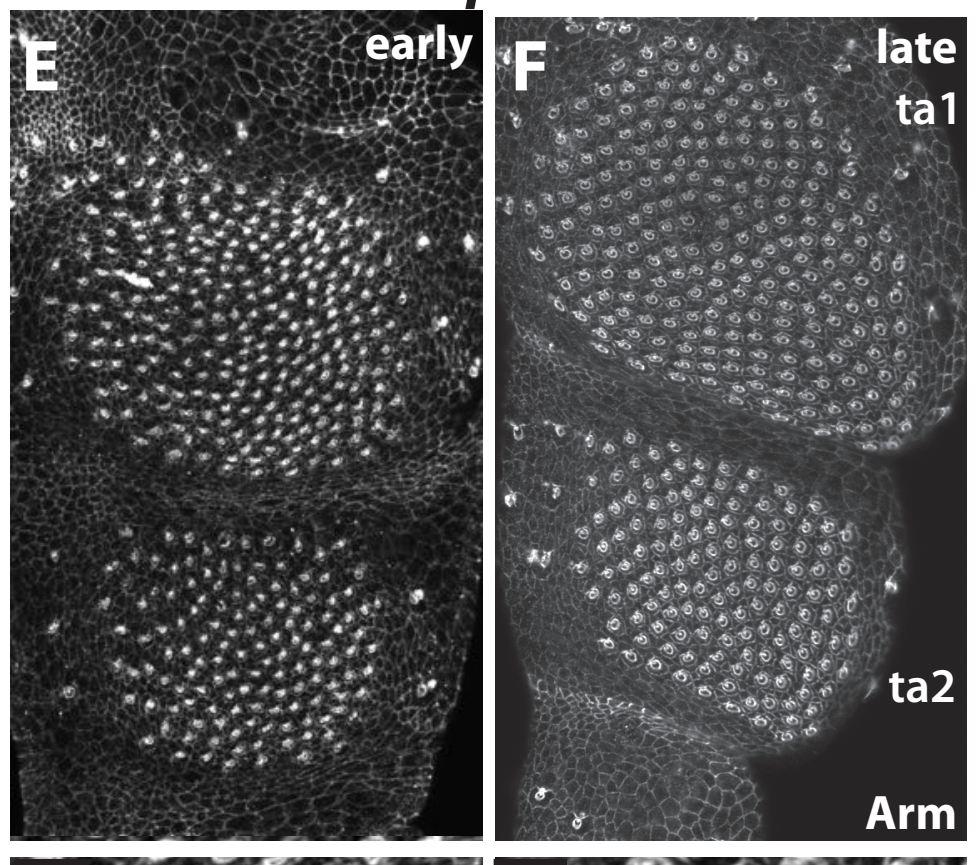

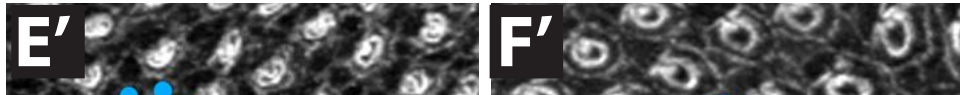

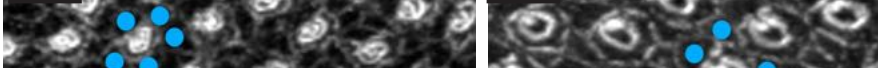

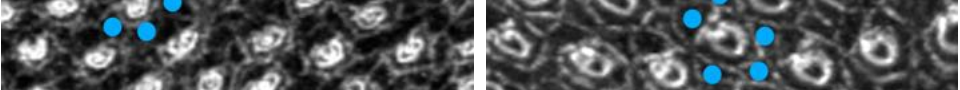

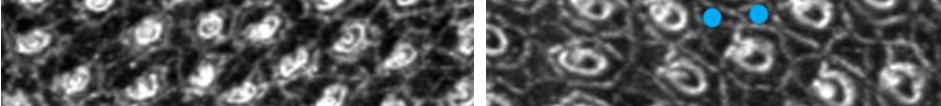

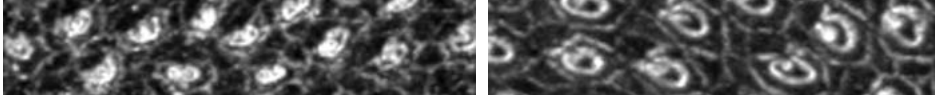

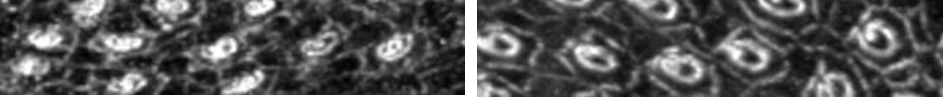
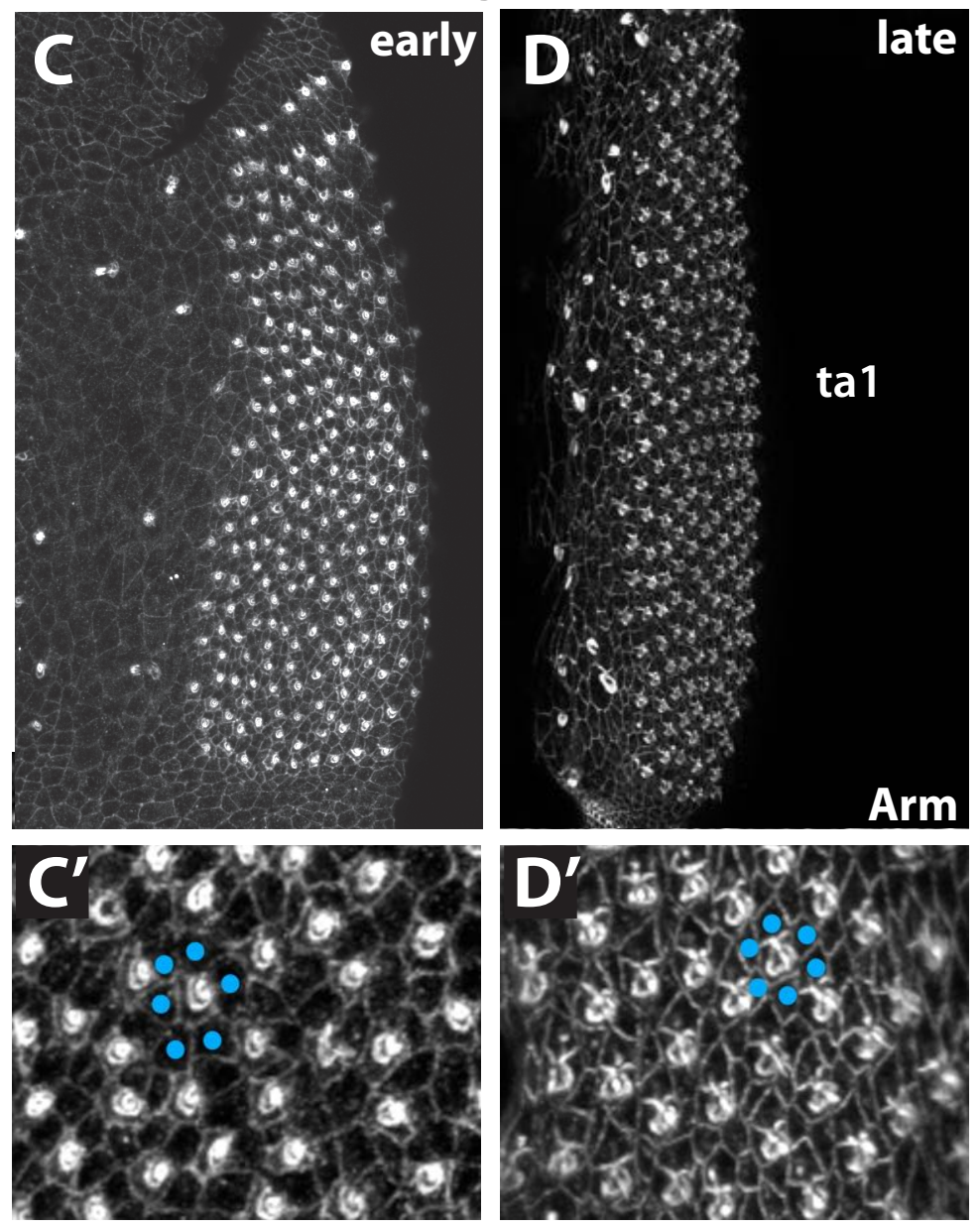

Z. tuberculatus

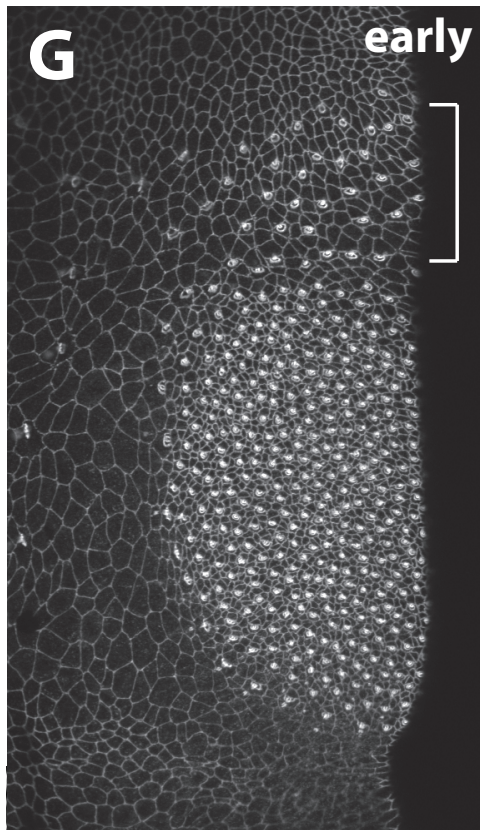

II

late

TBR

ta 1
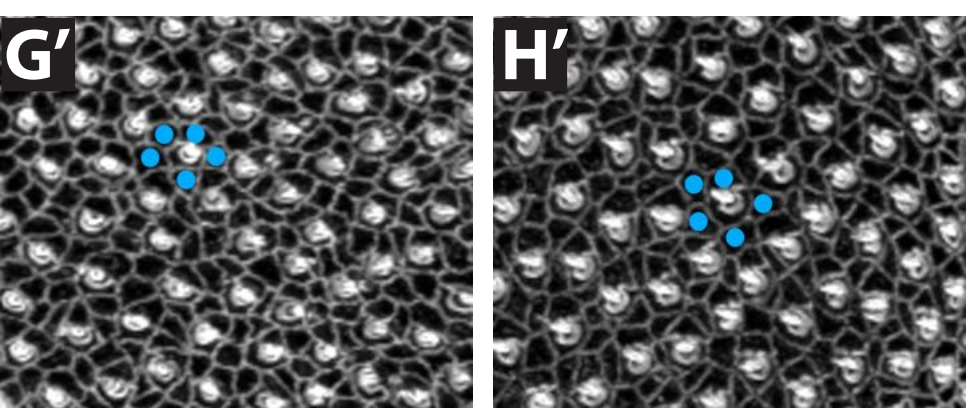